\title{
Profundidade de Semeadura e Presença de Palha Afetam a EMergência de PlÂntulas De Vernonia ferruginea
}

\author{
Sowing Depth and Presence of Straw affect Emergence of Vernonia ferruginea Seedling
}

\author{
ALBERGUINI, A.L. ${ }^{2}$ e YAMASHITA, O.M. ${ }^{3}$
}

\begin{abstract}
RESUMO - A compreensão sobre a biologia de plantas daninhas pode contribuir significativamente no estabelecimento de estratégias adequadas para seu manejo, além de possibilitar o desenvolvimento de ferramentas de controle não químico. O objetivo deste trabalho foi estudar o efeito de profundidade de semeadura, tipo de solo, tipo e quantidade de palha na emergência de plântulas de Vernonia ferruginea (assa-peixe). No primeiro experimento, sementes da espécie foram colocadas em dois substratos (terra e areia) e em sete profundidades $(0 ; 0,0025 ; 0,005 ; 0,01 ; 0,02 ; 0,04 ;$ e $0,08 \mathrm{~m})$. No segundo experimento, determinou-se o efeito de palha de cana-de-açúcar, capim-braquiária e milho em cinco quantidades $\left(0,0 ; 1,5 ; 3,0 ; 6,0 ;\right.$ e $\left.9,0 \mathrm{t} \mathrm{ha}^{-1}\right)$ na emergência de $V$. ferruginea. Maior emergência foi obtida na superficie e em $0,0025 \mathrm{~m}$ em ambos os substratos. A palha de milho foi a que mais inibiu a emergência de $V$. ferruginea, em todas as quantidades testadas.
\end{abstract}

Palavras-chave: assa-peixe, planta daninha, cobertura morta.

\begin{abstract}
Basic information on the biology of weeds can contribute significantly to building appropriate strategies for their management, and developing non-chemical control tools. The aim of this work was to study the effect of sowing depth, soil type, and litter type and amount on the emergence of Vernonia ferruginea seedlings. In the first experiment, seeds of this species were placed in two substrates (soil and sand) at seven depths (0,0.0025, 0.005, 0.01, 0.02, 0.04 and $0.08 \mathrm{~m}$ ). In the second experiment, the effect of sugarcane straw, signal grass and maize was determined in five amounts $\left(0.0,1.5,3.0,6.0\right.$ and $9.0 \mathrm{t} \mathrm{ha^{-1 } )}$ on the emergence of V. ferruginea. The highest emergence was observed on the surface and at $0.0025 \mathrm{~m}$ in both substrates. Corn straw inhibited emergence of $\boldsymbol{V}$. ferruginea the most, in all the amounts tested.
\end{abstract}

Keywords: Vernonia ferruginea, weed, mulching.

\section{INTRODUÇÃO}

O estudo da biologia de espécies de plantas daninhas pode propiciar a geração de informações importantes para a adoção de novas técnicas de manejo que sejam práticas, eficientes, seguras e econômicas, visando à redução do uso de herbicidas (Guimarães et al., 2002). O fator principal de perdas de áreas de pastagem para as plantas daninhas é pela competição por água, luz, nutrientes, espaço e temperatura (Voll et al., 2003). Essas plantas apresentam basicamente as mesmas necessidades nutricionais das pastagens; entretanto, devido à sua maior habilidade em aproveitar esses nutrientes, conseguem acumulá-los em seus tecidos muito mais quantidades que as forrageiras (Lorenzi, 2000).

1 Recebido para publicação em 17.1.2010 e na forma revisada em 17.12.2010.

Parte da Monografia apresentada pela primeira autora para obtenção do título de Licenciada em Ciências Biológicas.

2 Bióloga, Universidade do Estado de Mato Grosso - UEMAT, Campus de Alta Floresta-MT, <alber_gui_ni@hotmail.com>;

${ }^{3}$ Engo - -Agr ${ }^{\circ}$, Prof. D.Sc., Departamento de Agronomia, Universidade do Estado de Mato Grosso, UEMAT, Campus de Alta Floresta

- MT, Rod. MT-208 km 147, Jd. Tropical, 78580-000 Alta Floresta-MT, <yama@unemat.br> 
Entre as muitas espécies invasoras das pastagens encontra-se a Vernonia ferruginea, conhecida popularmente como: assa-peixe, assa-peixe-do-pará e assa-peixe-de-santana. Essa planta é nativa do Brasil, ocorrendo na maior parte do território, com exceção da região Sul, porém muito comum em Mato Grosso e Pará (Kissmann \& Groth, 2000). É uma espécie perene, floresce nos meses de agosto a outubro e frutifica de novembro a março. Reproduz-se por sementes, que se dispersam por aquênios. É pouco exigente em relação ao tipo de solo, sendo muito competitiva em solos de cerrado (Lorenzi, 2000).

Estudos básicos sobre biologia germinativa de plantas daninhas e, em especial, daquelas que infestam áreas tropicais e subtropicais são importantes, pois a compreensão a respeito de informações básicas dessas plantas pode contribuir significativamente na construção de estratégias adequadas para seu manejo, além de possibilitar o desenvolvimento de técnicas alternativas de controle (Guimarães et al., 2002; Canossa et al., 2007).

A grande maioria das espécies daninhas, como $V$. ferruginea, reproduz-se por sementes, e o grande sucesso das sementes como órgão de perpetuação e disseminação dessas espécies deve-se à capacidade de distribuição da germinação ao longo do tempo (dormência e longevidade no solo) e do espaço (dispersão) (Merotto et al., 2002). Entretanto, ao longo do tempo, essas espécies evoluíram para a produção de grande quantidade de sementes, em detrimento do seu tamanho (Holzner et al., 1982), criando assim mecanismos para impedir que ocorra germinação em profundidades inadequadas no solo, já que a reduzida disponibilidade de reservas não seria suficiente para suportar o crescimento da plântula até a emergência (Guimarães et al., 2002).

A presença de palha sobre o solo é uma importante forma de controle de plantas daninhas. Essa supressão por coberturas mortas é atribuída a fatores de natureza física, química e biológica, sendo amplamente estudada para cultivos anuais (Teasdale $\&$ Mohler, 1993; Correia \& Durigan, 2004; Trezzi \& Vidal, 2004; Correia et al., 2006). A manutenção da pastagem, pela adoção de pastejo e outras práticas, permite que o solo mantenha-se constantemente coberto, evitando dessa forma a ocupação pela flora infestante, oriunda do banco de sementes (Pereira et al., 2001).

O objetivo deste trabalho foi estudar o efeito de profundidade de semeadura, tipo de solo, tipo e quantidade de palha na emergência de plântulas de Vernonia ferruginea.

\section{MATERIAL E MÉTODOS}

Foram desenvolvidos dois experimentos em viveiro telado (com retenção de $30 \%$ de luz) da Universidade do Estado de Mato Grosso (UNEMAT), campus universitário de Alta Floresta - MT.

Os aquênios foram coletados em áreas de pastagem no município de Alta Floresta-MT. Foram utilizados apenas aqueles que se desprenderam da inflorescência após agitação. Eles foram secos ao ar por 72 horas, em local ventilado e seco. Posteriormente, foi realizada seleção visual, descartando-se impurezas, aquênios chochos ou com qualquer sinal de dano ou deterioração. Após o período de secagem e seleção, os aquênios foram acondicionados em sacos de papel e armazenados em refrigerador mantido a $\pm 10{ }^{\circ} \mathrm{C}$.

Para os dois experimentos, o delineamento experimental foi inteiramente ao acaso, com quatro repetições de 50 aquênios em cada unidade experimental. Os dados foram submetidos à análise de variância, e as médias de emergência final e índice de velocidade de emergência (IVE) foram comparadas pelo teste de Tukey a $5 \%$ de probabilidade. Para as variáveis quantitativas, realizou-se análise de regressão.

\section{Substrato e profundidade de semeadura}

Foram utilizados como substrato solos de mata (primeiros 0,20 m) e areia, ambos peneirados para retirada de impurezas e acondicionados em vasos plásticos com capacidade para 2,0 L de substrato. A análise química e física de uma amostra do solo utilizado no experimento encontra-se na Tabela 1.

As profundidades estudadas foram: 0 ; 0,$0025 ; 0,005 ; 0,01 ; 0,02 ; 0,04 ;$ e $0,08 \mathrm{~m}$, sendo distribuídas as sementes de $V$. ferruginea em cada profundidade. Após a semeadura, a umidade dos substratos foi controlada por 
Tabela 1 - Características físicas e químicas de uma amostra de solo utilizada nos experimentos de profundidade de semeadura e presença de palha

\begin{tabular}{|c|c|c|c|c|c|c|c|c|c|}
\hline \multicolumn{10}{|c|}{ Análise química } \\
\hline \multirow{2}{*}{$\begin{array}{c}\mathrm{pH} \\
\left(\mathrm{H}_{2} \mathrm{O}\right)\end{array}$} & \multirow{2}{*}{$\begin{array}{c}\mathrm{MO} \\
\left(\mathrm{g} \mathrm{dm}^{-3}\right)\end{array}$} & \multirow{2}{*}{$\begin{array}{c}\mathrm{P} \\
\left(\mathrm{mg} \mathrm{dm}^{-3}\right)\end{array}$} & $\mathrm{K}$ & $\mathrm{Ca}$ & $\mathrm{Mg}$ & $\mathrm{H}+\mathrm{Al}$ & SB & $\mathrm{T}$ & \multirow{2}{*}{$\begin{array}{c}\mathrm{V} \\
(\%)\end{array}$} \\
\hline & & & \multicolumn{6}{|c|}{$\mathrm{cmol}_{\mathrm{c}} \mathrm{dm}^{-3}$} & \\
\hline 6,1 & 16,0 & 6,0 & 0,21 & 3,0 & 0,9 & 1,9 & 4,1 & 6,0 & 68,3 \\
\hline \multicolumn{10}{|c|}{ Análise física } \\
\hline \multicolumn{2}{|c|}{ areia } & \multicolumn{2}{|c|}{ silte } & \multirow{2}{*}{\multicolumn{2}{|c|}{ argila }} & & \multirow{2}{*}{\multicolumn{2}{|c|}{ Classe textural }} & \\
\hline \multicolumn{4}{|c|}{$\left(\mathrm{g} \mathrm{kg}^{-1}\right)$} & & & & & & \\
\hline \multicolumn{2}{|c|}{440} & \multicolumn{2}{|c|}{110} & \multicolumn{2}{|c|}{450} & & \multicolumn{2}{|c|}{ argiloso } & \\
\hline
\end{tabular}

Análise realizada no Laboratório Plante Certo - Várzea Grande-MT.

subirrigação, fornecendo-se água diariamente, visando manter o substrato umedecido a aproximadamente $80 \%$ da capacidade de campo.

O experimento foi realizado em esquema fatorial $2 \times 7$ (dois tipos de substrato e sete profundidades de semeadura).

Foram realizadas contagens diárias das plântulas emersas por 60 dias. De posse dos dados, calculou-se a emergência acumulada e o IVE, utilizando a fórmula proposta por Maguire (1962):

$$
\mathrm{IVE}=E_{1} / N_{1}+E_{2} / N_{2}+\ldots+E_{n} / N_{n}
$$

em que: $\operatorname{IVE}=$ indice de velocidade de emergência; $E_{1}, E_{2}, E_{n}=$ número de plântulas emersas computadas na primeira, segunda e última contagens; e $N_{1}, N_{2}, N_{n}=$ número de dias de semeadura na primeira, segunda e última contagens.

\section{Cobertura vegetal}

Foram utilizados vasos plásticos $(2,0 \mathrm{~L}$ de capacidade), perfurados no fundo, preenchidos com o mesmo solo utilizado no experimento anterior. A semeadura de $V$. ferruginea foi feita depositando-se os aquênios a $0,005 \mathrm{~m}$ de profundidade. Após a semeadura, cobriu-se a superficie do solo com quantidades crescentes $(0,0$; 1,5; 3,0; 6,0; e 9,0 t ha-1) de três tipos de palha (cana-de açúcar, milho e capim-braquiária), de acordo com o tratamento. A umidade do solo foi controlada por subirrigação, também como descrito no experimento anterior.
Para obtenção da palha, as partes aéreas das espécies foram colhidas de cultivos na região. Posteriormente, elas foram cortadas em partículas de tamanho inferior a 0,03 $\mathrm{m} \mathrm{e}$ secas em estufa de circulação forçada de ar a $60{ }^{\circ} \mathrm{C}$ por cinco dias.

$\mathrm{O}$ experimento foi realizado em esquema fatorial $3 \times 5$ [três tipos de palha (cana-de açúcar, milho e braquiária) e cinco quantidades $\left(0,0 ; 1,5 ; 3,0 ; 6,0 ;\right.$ e $\left.\left.9,0 \mathrm{t} \mathrm{ha}^{-1}\right)\right]$.

Após a semeadura, foram realizadas avaliações diarias por 40 dias, contando-se as plântulas que emergiam. De posse dos dados, calculou-se o IVE e a emergência acumulada, como descrito anteriormente. $\mathrm{O}$ experimento foi mantido por mais 40 dias, avaliando-se a emergência de plântulas após a retirada da palha.

\section{RESULTADOS E DISCUSSÃO}

\section{Tipo de substrato e profundidade}

Para o experimento de profundidade e substrato, houve significância para profundidade $(p<0,05)$, para substrato $(p<0,05)$ e para interação da profundidade com substrato $(\mathrm{p}<0,05)$.

Em ambos os substratos testados, a manutenção das sementes na superfície permitiu maior taxa de emergência de plântulas. Nas maiores profundidades estudadas, observaram-se poucas plântulas emersas, seguindo tendência linear para o substrato solo e exponencial para areia (Figura 1). 


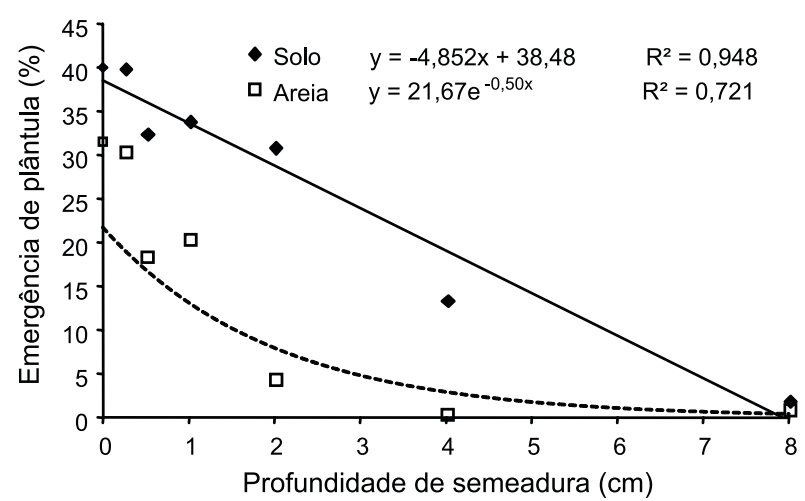

Figura 1 - Emergência de plântulas (\%) de Vernonia ferruginea em solo de mata e areia em diferentes profundidades de semeadura. Alta Floresta-MT, 2009.

Tanto no solo como na areia, não houve diferença de emergência entre as profundidades de 0,0 e 0,0025 m, sendo esta de $40 \%$ no solo e $30 \%$ na areia. Entre 0,005 e 0,02 m, a emergência manteve-se próxima a $33 \% \mathrm{em}$ solo, sendo reduzida para $13 \%$ a $0,04 \mathrm{~m}$ e não mais que $2 \%$ a $0,08 \mathrm{~m}$ de profundidade. $\mathrm{Na}$ areia, a emergência manteve-se próxima de $20 \%$ entre 0,005 e $0,01 \mathrm{~m}$ e reduzida significativamente a partir dessa profundidade, variando entre 0,5 e $4,5 \%$ nas maiores profundidades.

Esses resultados assemelham-se aos encontrados por Guimarães et al. (2002) para Tridax procumbens, por Dias Filho (1996) para Stachytarpheta cayennensis, por Norsworthy \& Oliveira (2005) para Cassia occidentalis e por Abreu \& Garcia (2005) para as espécies de Xyris, que, além de apresentarem sementes pequenas e fotoblásticas positivas, são capazes de germinar apenas nas camadas superficiais do solo, não superiores a $0,005 \mathrm{~m}$.

De acordo com Canossa et al. (2007), a maior emergência na superficie do solo, também observada em Alternanthera tenella, pode ser explicada pelo fato de as sementes serem mantidas sempre úmidas, evitando o ressecamento e permitindo o suprimento de água suficiente para ativar os mecanismos de germinação. Também, elas encontram-se mais expostas à luz e flutuações de temperaturas, o que contribui para aumentar a emergência, como citado em outros trabalhos, como os de Drew \& Brocklehurst (1984) e Ghersa et al. (1992).
O tamanho das sementes possui relação direta com os processos de germinação, crescimento e estabelecimento das plântulas, pois existe relação entre o tamanho das sementes e a necessidade de luz para germinação. Espécies com sementes pequenas, geralmente, requerem luz para a germinação (Venable \& Brow, 1988; Vieira, 2007), o que resulta no impedimento do processo germinativo em profundidade no solo. Nesses casos, a plântula apresenta dificuldade de emergir quando enterrada em maiores profundidades (Pearson et al., 2003), pois suas reservas seriam esgotadas antes que a plântula alcançasse a superfície do solo e iniciasse o processo fotossintético (Bewley \& Black, 1994).

Com o aumento da profundidade de semeadura, mesmo em condições adequadas de umidade no substrato há redução na germinação, pois, quanto mais profunda a semente se encontra, menos estímulos luminosos, e, não recebendo luz suficiente, não respondem às flutuações de temperaturas, que diferem em intensidade (Toledo et al., 1993). Todos esses fatores, associados à pouca capacidade de energia de sementes de $V$. ferruginea em razão de seu peso diminuto, causam a redução da emergência, uma vez que maiores profundidades representam um impedimento físico para essa plântula (Canossa et al., 2007).

Quanto ao índice de velocidade de emergência, houve significância para profundidades $(p<0,05)$, para substratos $(p<0,05)$ e para a interação dos fatores $(p<0,05)$.

$O$ indice de velocidade de emergência foi significativamente maior para sementes posicionadas na superficie do solo (Figura 2), em relação àquelas em profundidade. Maiores valores de IVE foram observados a 0 e 0,02 m, cujos valores variaram entre 1,64 e $0,92 \%$. Para o substrato areia, os maiores percentuais de IVE foram obtidos até a $0,0025 \mathrm{~m}$, onde os valores foram próximos a $1 \%$. Resultados esses concordantes com os de Barbosa et al. (1991), os quais verificaram que, para plântulas do gênero Digitaria, os níveis mais altos de velocidade de emergência encontram-se na superfície do solo, e os de Muniz Filho et al. (2004) para Bidens pilosa, em que a velocidade de emergência reduzia significativamente com o aumento da profundidade de semeadura. 


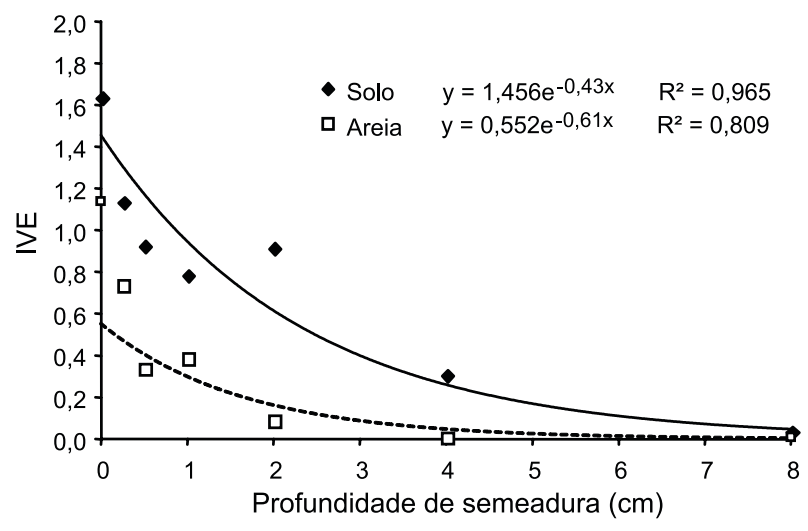

Figura 2 - Indice de velocidade de emergência (IVE) de Vernonia ferruginea em solo de mata e areia em diferentes profundidades de semeadura. Alta Floresta-MT, 2009.

Para o substrato solo, as profundidades de 0,0025 a 0,02 m não diferiram e, para o substrato areia, as profundidades de 0,005 e 0,01 m e entre 0,02 e 0,04 $\mathrm{m}$ também não diferiram; na profundidade de $0,08 \mathrm{~m}$, não houve diferença do índice de velocidade de emergência para ambos os substratos. Resultado semelhante foi verificado por Toledo et al. (1993) com Xanthium strumarium, o qual emergiu mais rapidamente a partir de 0,08 $\mathrm{m}$ de profundidade.

Oliveira Jr. \& Delistoianov (1996), depositando sementes de Desmodium purpureum em diferentes profundidades, observaram que nas profundidades inferiores a $0,0375 \mathrm{~m}$ o indice de velocidade de emergência ocorreu de forma rápida e concentrada, o que está em conformidade com os resultados obtidos no presente trabalho.

A emergência acumulada, ao longo dos 60 dias de avaliação do experimento, encontra-se na Figura 3. Os maiores percentuais, obtidos na superficie do solo, foram observados a partir dos 45 dias da semeadura, atingindo $50 \%$ de plântulas emersas em substrato de solo e $39 \%$ no de areia. A $0,0025 \mathrm{~m}$, onde o percentual também foi de $50 \%$ no solo e $38 \%$ na areia, esses valores foram atingidos aos 57 e 49 dias, respectivamente.

\section{Tipo e quantidade de palha}

Para o estudo do efeito da palha na emergência de plântulas de $V$. ferruginea, houve significância para $o$ tipo de palha $(p<0,05)$, para a quantidade $(\mathrm{p}<0,05)$ e também para a interação de palha com quantidade $(p<0,05)$.
Em todos os tipos de palha estudados, houve redução significativa do número de plântulas emergidas a partir de $1,5 \mathrm{t} \mathrm{ha}^{-1}$, seguindo uma função exponencial (Figura 4). Em relação à ausência de palha, a redução foi de $65 \%$ com a palha de milho, $55 \%$ com a de capim-braquiária e $37 \%$ com a de cana-deaçúcar, quando da presença de 1,5 t ha-1.

As coberturas que mais impediram a emergência de plântulas foram as palhas de milho e capim-braquiária, em todas as quantidades testadas. Resultados semelhantes foram obtidos em trabalho realizado por Trezzi $\&$ Vidal (2004), os quais observaram que, para Brachiaria plantaginea, 1,3 $\mathrm{t} \mathrm{ha}^{-1}$ de palha de sorgo foi suficiente para reduzir $50 \%$ da infestação dessa planta daninha, e para Sida rhombifolia e Bidens pilosa a emergência destas foi significativamente reduzida quando cobertas com 4,0 tha he $^{-1}$ de palha de milheto. Oliveira et al. (2001) estimaram que, para cada tonelada de milho adicionada à superficie do solo, aumentava-se em 4\% o controle de plantas daninhas.

A cobertura com palha de cana-de-açúcar foi a que proporcionou maior percentual médio de emergência de $V$. ferruginea, em relação às demais coberturas, em todas as quantidades, concordando com Correia \& Durigan (2004), que estudaram a emergência de Ipomoea quamoclit. Mesmo assim, esta (cana-de-açúcar), no tratamento com $1,5 \mathrm{t} \mathrm{ha}^{-1}$, reduziu $37 \%$ em relação à testemunha, demonstrando sua capacidade de redução da emergência dessa planta daninha.

O número de plântulas emergidas na testemunha foi sempre superior ao dos demais tratamentos estudados. A ação supressora da cobertura deve-se ao efeito físico sobre as sementes fotoblásticas positivas e para aquelas que necessitam de grande amplitude de variação térmica diária para iniciar o processo germinativo (Vidal \& Theisen, 1999). Além disso, o efeito físico da cobertura morta reduz as chances de sobrevivência das plântulas com pequena quantidade de reservas nas sementes (Correia et al., 2006). As sementes das espécies fotoblásticas positivas, mantidas em maiores profundidades no solo, não recebem a indução luminosa para garantir o processo germinativo e, consequentemente, não respondem às outras condições ambientais 
(A)

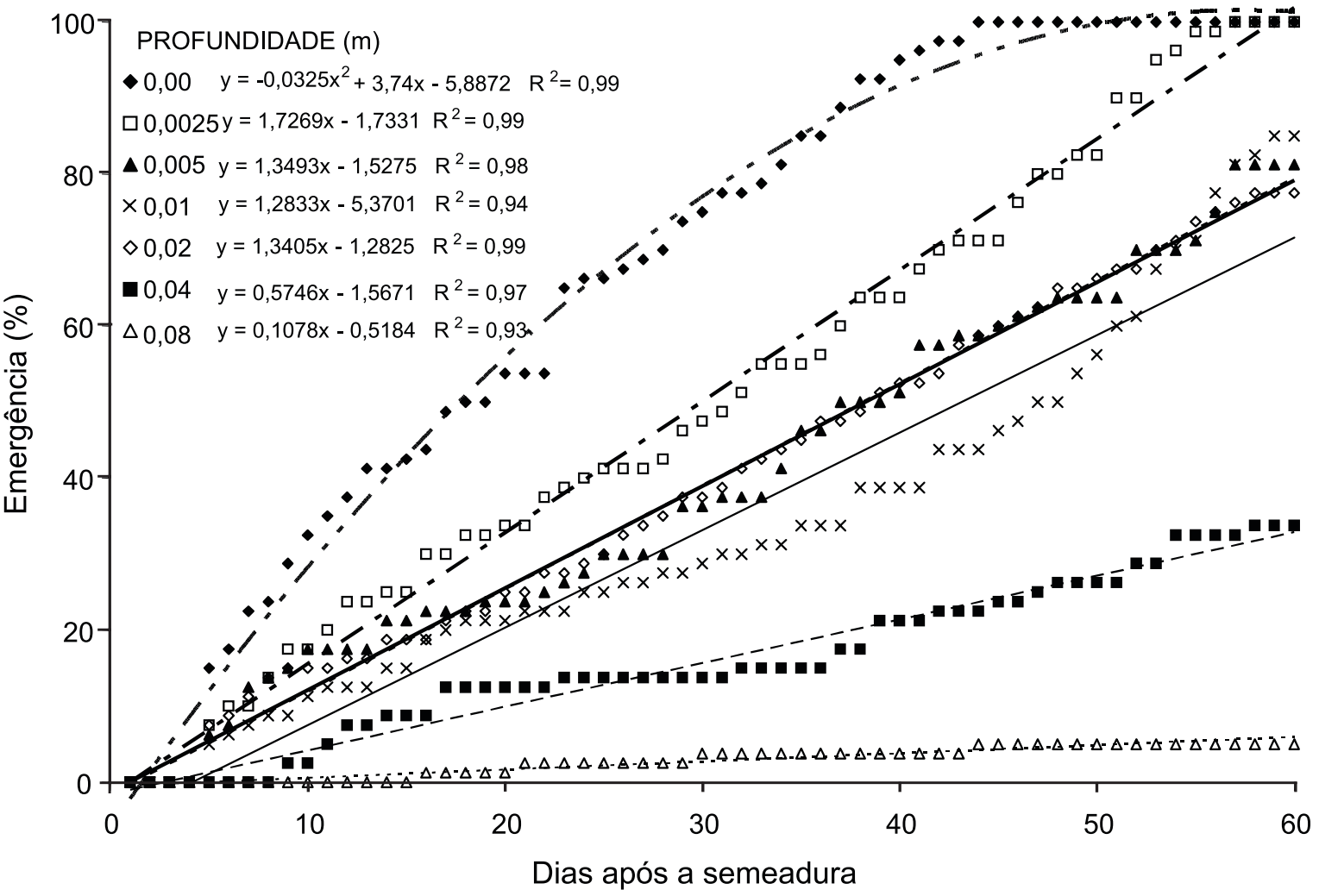

(B)

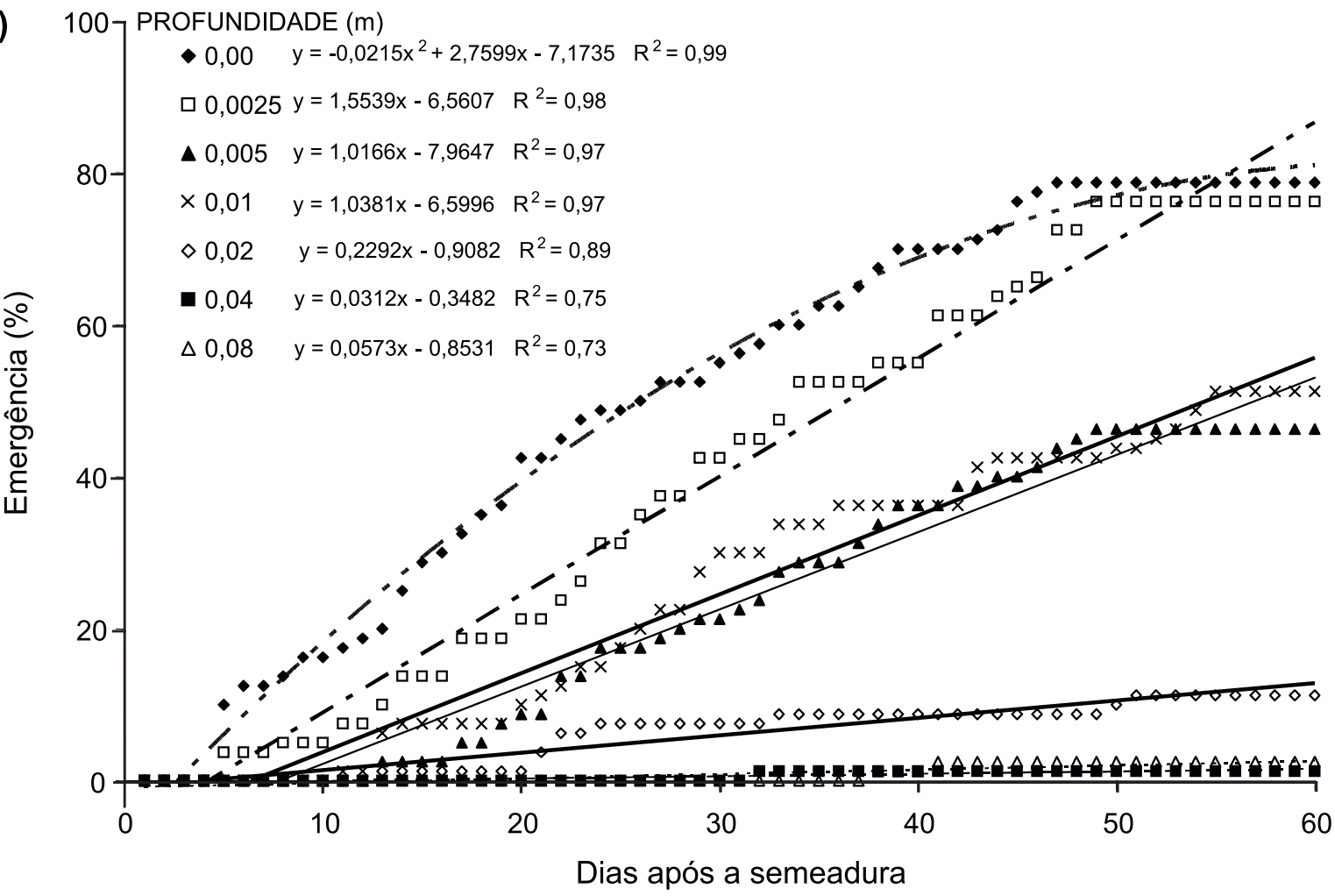

Figura 3 - Emergência acumulada de Vernonia ferruginea em diferentes profundidades de semeadura, em solo (A) e areia (B). Alta Floresta-MT, 2009 


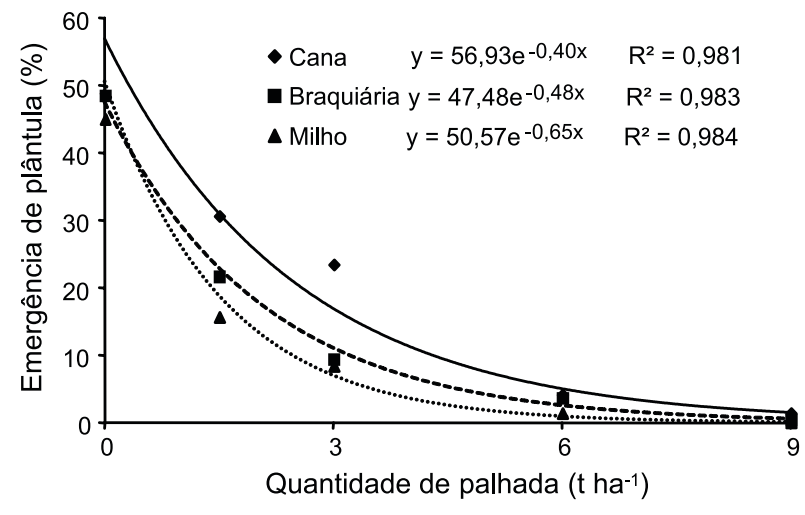

Figura 4 - Emergência de Vernonia ferruginea submetida a tipos e quantidades de palha. Alta Floresta-MT, 2009.

indicativas de ambiente favorável, como temperatura e umidade; da mesma maneira, sementes posicionadas na superficie do solo, mas sob vegetação adulta ou resíduos vegetais (palha), também não responderiam aos outros estimulos ambientais, por estarem no escuro (Ghersa et al., 1992).

Após a retirada da palha, houve aumento no número de plântulas emergidas em todos os tratamentos, exceto na testemunha, na qual a emergência se manteve praticamente inalterada (Figura 5). Apesar desse aumento, ele não foi suficiente para atingir valores da testemunha. Diversas causas podem estar relacionadas com esses resultados: as sementes podem ter sido atacadas por microrganismos ou insetos; elas também podem ter germinado, porém não conseguiram romper a camada de palha; ou pode ter ocorrido déficit de fatores essenciais para a emergência das plantas, como hidratação excessiva, ou falta de luz.

Martins et al. (1999), estudando a cobertura do solo com palha de cana, verificaram que ela reduziu significativamente a emergência das plântulas de Sida rhombifolia, sendo esse efeito mais intenso quanto maior a quantidade de palha. No entanto, a retirada desta promoveu a emergência das plântulas dessa espécie, devido à superação da dormência causada ou mantida pela cobertura morta.

Durigan et al. (2004) mencionaram que o solo coberto com $12 \mathrm{t} \mathrm{ha}^{-1}$ de palha de cana proporcionou maior controle de plantas daninhas e que, com a retirada total da palha, não houve controle.

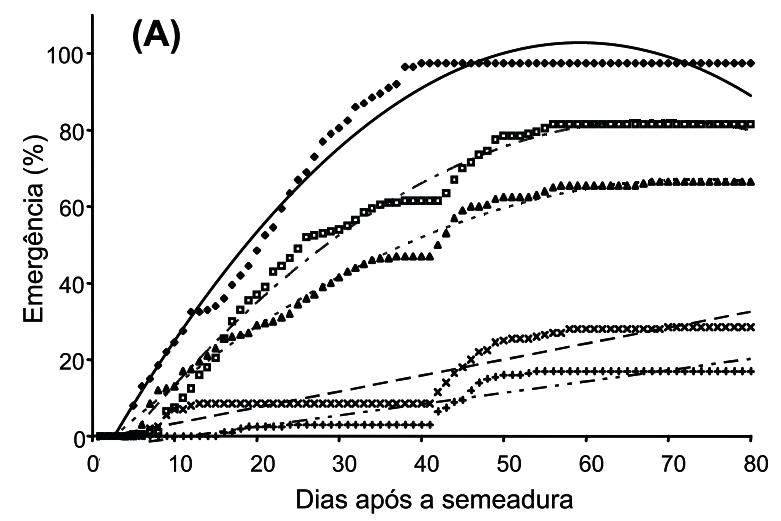

QUANTIDADE DE $\bullet 0,0 y=-0,0321 x^{2}+3,807 x-9,9291 R^{2}=0,98$ PALHADA (t ha-1) $\quad 1,5 y=-0,0202 x^{2}+2,766 x-12,319 R^{2}=0,99$ $\triangle 3,0 y=0,4169 x-0,821 R^{2}=0,89$

$\times 6,0 y=-0,0132 x^{2}+1,9562 x-5,144 R^{2}=0,99$

$+9,0 y=0,2956 x-3,4331 R^{2}=0,87$

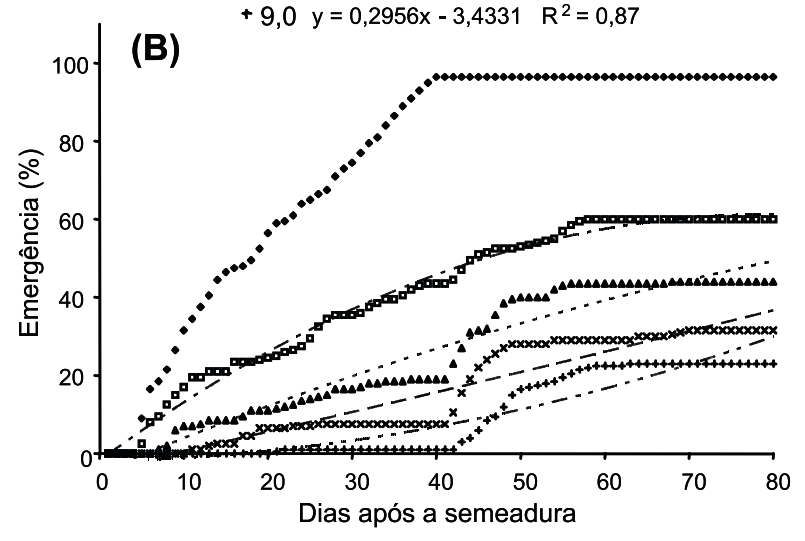

QUANTIDADE DE $\bullet 0,0 \quad y=-0,0101 x^{2}+1,5949 x-1,8621 \quad R^{2}=0,99$ PALHADA (t ha-1) $\quad 1,5 \quad y=-0,0297 x^{2}+3,5292 x-3,7391 R^{2}=0,99$ $\Delta 3,0 y=0,0003 x^{2}+0,4879 x-4,3118 R^{2}=0,90$ $\times 6,0 y=-0,0029 x^{2}+0,9083 x-4,8641 R^{2}=0,94$ $+9,0 y=0,0045 x^{2}+0,0403 x-1,9213 R^{2}=0,87$

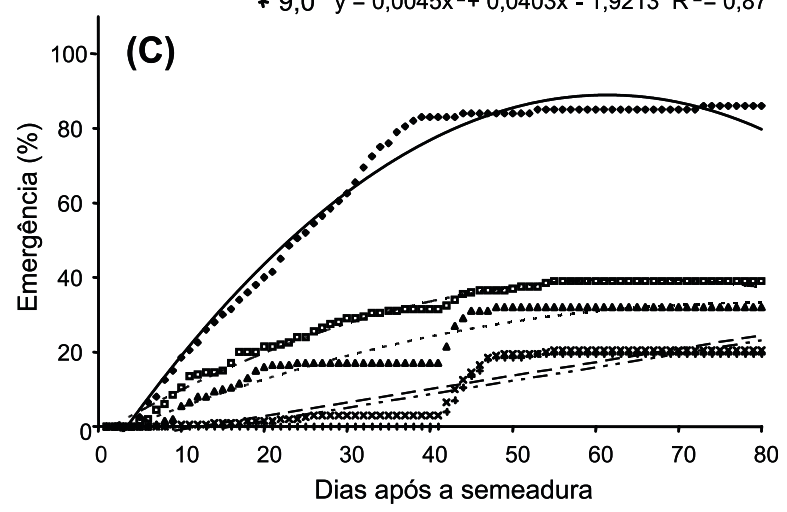

QUANTIDADE DE $\bullet 0,0 \quad y=-0,0099 x^{2}+1,2876 x-2,0576 R^{2}=0,99$ PALHADA (t ha-1) $\quad$ a 1,5 $y=-0,0265 x^{2}+3,2557 x-10,994 \quad R^{2}=0,98$ $\Delta 3,0 y=-0,0058 x^{2}+0,9214 x-3,4584 R^{2}=0,94$ $\times 6,0 y=0,3611 x-4,4101 R^{2}=0,85$

$+9,0 y=0,361 x-5,7837 R^{2}=0,79$

Figura 5 - Emergência acumulada de Vernonia ferruginea submetida a quantidades e tipos de palha (A - cana; B braquiária; C - milho). Alta Floresta-MT, 2009 
Em relação ao solo coberto com palha de capim-braquiária, houve inibição da emergência de $V$. ferruginea para todas as quantidades testadas, mas na cobertura de $6 \mathrm{t} \mathrm{ha}^{-1}$ não houve diferença significativa entre a palha de cana e a de capim-braquiária. Entre 3 e $9 \mathrm{t} \mathrm{ha}^{-1}$, não houve diferença entre a palha de milho e a de capim-braquiária. Souza Filho et al. (1997) indicam a existência de potencial alelopático de capim-braquiária sobre a germinação e o desenvolvimento de plantas daninhas de pastagem, como Sida rhombifolia e $V$. polianthes.

Ressalta-se ainda que o processo de decomposição da cobertura morta na superficie do solo pode liberar gradativamente diversos aleloquímicos, que podem interferir na germinação e emergência das plantas daninhas, além da perda da viabilidade das sementes decorrente do desenvolvimento de insetos e microrganismos, que se alimentam ou hospedam as sementes e a parte aérea das plantas daninhas (Correia \& Durigan, 2004).

Menores valores de IVE foram obtidos em palha de milho em todas as quantidades testadas. Nessa palha, para essa variável, não se observou diferença entre as duas maiores quantidades. Para todos os tipos de palha estudados, à medida que a quantidade foi aumentada, observou-se redução do IVE, seguindo tendência exponencial (Figura 6).

O tipo e quantidade de cobertura morta é um fator de significativa importância, visto que em quantidades similares há respostas

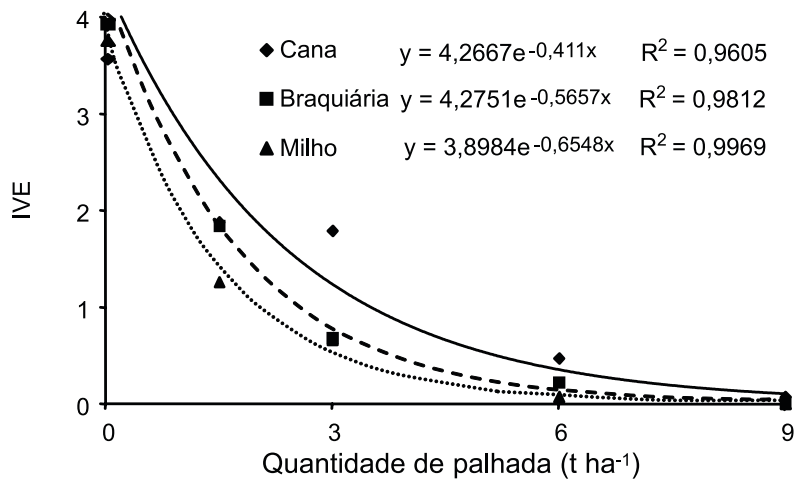

Figura 6 - Índice de velocidade de emergência (IVE) de sementes de Vernonia ferruginea submetidas a quantidades e tipos de palha. Alta Floresta-MT, 2009 distintas para a mesma espécie de planta daninha. Trezzi et al. (2006) estudaram o efeito da palha de milho, sorgo e aveia sobre a emergência e o desenvolvimento de plântulas de leiteiro (Euphorbia heterophylla) e verificaram que o IVE foi reduzido linearmente em função do aumento de palha de milho na superficie do solo, o que está em concordância com os resultados deste trabalho.

Nas condições do desenvolvimento do presente trabalho, conclui-se que o substrato que promove maior emergência de plântula é o solo de mata, em relação à areia; maior emergência é obtida até a profundidade de até $0,0025 \mathrm{~m}$ em ambos os substratos; e a palha que mais impede a emergência de $V$. ferruginea é a de milho, até 9,0 t ha ${ }^{-1}$.

\section{LITERATURA CITADA}

ABREU, M. E. P.; GARCIA, Q. S. Efeito da luz e da temperatura na germinação de sementes de quatro espécies de Xyris L. (Xyridaceae) ocorrentes na Serra do Cipó, MG, Brasil. Acta Bot. Bras., v. 19, n. 1, p. 149-154, 2005

BARBOSA, J. M. et al. Germinação e emergência de plântulas para três espécies de gramíneas invasoras de cultura do gênero Digitaria Heisler ex Haller. Acta Bot. Bras., v. 1, n. 3, p. 7-13, 1991

BEWLEY, J. D.; BLACK, M. Seeds: physiology of development and germination. 2.ed. New York: Plenum, 1994 $445 \mathrm{p}$

CANOSSA, R. S.et al. Profundidade de semeadura afetando a emergência de plântulas de Alternanthera tenella. Planta Daninha, v. 25, n. 4, p. 719-725, 2007.

CORREIA, N. M.; DURIGAN, J. C. Emergência de plantas daninhas em solo coberto com palha de cana-de-açúcar. Planta Daninha, v. 22, n. 1, p. 11-17, 2004

CORREIA, N. M.; DURIGAN, J. C.; KLINK, U. P. Influência do tipo e da quantidade de resíduos vegetais na emergência de plantas daninhas. Planta Daninha, v. 24, n. 2, p. 245-253, 2006.

DIAS FILHO, M. B. Germination and emergence of Stachytarpheta cayennensis and Ipomoea asarifolia. Planta Daninha, v. 14, n. 2, p. 118-126, 1996.

DREW, R. L. K.; BROCKLEHURST, P. A. Investigations on the control of lettuce seeds germination at high temperatures. J. Exper. Bot., v. 35, n. 156, p. 986-993, 1984. 
DURIGAN, J. C.; TIMOSSI, P. C.; LEITE, G. J. Controle químico da tiririca (Cyperus rotundus), com e sem cobertura do solo pela palha de cana-de-açúcar. Planta Daninha, v. 22, n. 1, p. 127-135, 2004.

GHERSA, C. M.; BENECH, R. L.; MARTINEZ-GHERSA, M. A. The role of fluctuating temperatures in germination and establishment of Sorghum hapelense. Regulation of germination at increasing depths. Func. Ecol., v. 6, n. 4, p. 460-468, 1992.

GUIMARÃES, S. C.; SOUZA, I. F.; PINHO, E. V. R. V. Emergência de Tridax procumbens em função da profundidade de semeadura, do conteúdo de argila no substrato e da incidência de luz na semente. Planta Daninha, v. 20, n. 3, p. 413-419, 2002.

HOLZNER, W.; HAYASHI, I.; GLAUNINGER, J. Reproductive strategy of annual agrestals. In: HOLZNER, W.; NUMATA, M. (Eds.). Biology and ecology of weeds. Hague: Junk Publishers, 1982. p. 111-121.

KISSMANN, K. G.; GROTH, D. Plantas infestantes e nocivas. São Paulo: BASF, 2000. 726 p.

LORENZI, H. Plantas daninhas do Brasil. Nova Odessa: Plantarum, 2000. 477 p

MAGUIRE, J. D. Speed of germination-and in selection and evaluation for seeding emergence and vigor. Crop Sci., v. 2 , n. 2, p. 176-177, 1962.

MARTINS, D. et al. Emergência em campo de dicotiledôneas infestantes em solo coberto com palha de cana-de-açúcar.

Planta Daninha, v. 17, n. 1, p. 151-161, 1999.

MEROTTO Jr. A.; VIDAL, R.A.; FLECK, N.G.; ALMEIDA, M.L. Interferência da plantas daninhas sobre o desenvolvimento inicial de plantas de soja e arroz através da qualidade da luz. Planta Daninha, Viçosa, v.20, n.1, p.9-16, 2002.

MUNIZ FILHO, A. et al. Capacidade de emergência de picão preto em diferentes profundidades de semeadura. R. Biol. Ci. Terra, v. 4, n. 1, p. 28, 2004.

NORSWORTHY. J. K.; OLIVEIRA. J. M. Coffee senna (Cassia occidentalis) germination and emergence is affected by environmental factors and seeding depth. Weed Sci., v. 53, p. 657-662, 2005.

OLIVEIRA, M. F. et al. Efeito da palha e da mistura atrazine e metolachlor no controle de plantas daninhas na cultura do milho, em sistema de plantio direto. Pesq. Agropec. Bras., v. 36, n. 1, p. $37-41,2001$.
OLIVEIRA Jr., R. S.; DELISTOIANOV, F. Profundidade de semeadura e métodos de quebra de dormência afetando a germinação de Desmodium purpureum (Mill) Fawc. et Rend. (Leguminosae-Papilionoideae). R. Bras. Bot., v. 19, n. 2, p. 221-225, 1996.

PEARSON, T.R.H. et al. Functional significance of photoblastic germination in neotropical pioneer trees: a seed's eye view. Func. Ecol., v. 17, p. 394-402, 2003.

PEREIRA, R. C.; CARMONA, R.; ARAUJO NETO, B. S. C. Controle de Acacia fornesiana e de Mimosa pteridofita em pastagem. Pesq. Agropec. Bras, v. 36, n. 10, p. 1301-1307, 2001.

SOUZA FILHO, A. P. S.; RODRIGUES, L. R. A.; RODRIGUES, T. J. D. Potencial alelopático de forrageiras tropicais: efeitos sobre invasoras de pastagens.

Planta Daninha, v. 15, n. 1, p. 53-60, 1997

TEASDALE, J.R.; MOHLER, C.L. Light transmittance, soil temperature, and soil moisture under residue of hairy vetch and rye. Agron. J., v. 85, n. 3, p. 673-680, 1993.

TOLEDO, R. E. B.; KUVA, M. A.; ALVES, P. L. C. A. Fatores que afetam a germinação e a emergência de Xanthium strumarium L.: dormência, qualidade de luz e profundidade de semeadura. Planta Daninha, v. 11, n. 1/2, p. 15-20, 1993.

TREZZI, M. M. et al. Efeitos de resíduos da parte aérea de sorgo, milho e aveia na emergência e no desenvolvimento de plântulas de leiteiro (Euphorbia heterophylla) resistentes a inibidores de ALS. Planta Daninha, v. 24, n. 3, p. 443-450, 2006.

TREZZI, M. N.; VIDAL, R. A. Potencial de utilização de cobertura vegetal de sorgo e milheto na supressão de plantas daninhas em condição de campo: II - Efeitos da cobertura morta. Planta Daninha, v. 22, n. 1. p. 1-10, 2004.

VENABLE, D. L.; BROWN, J. S. The selective interactions of dispersal, dormancy and seed size as adaptations for reducing risk in variable environments. Am. Nat., v. 131, n. 3, p. 360-384, 1988.

VIDAL, R. A.; THEISEN, G. Efeito da cobertura do solo sobre a mortalidade de sementes de capim-marmelada em duas profundidades no solo. Planta Daninha, v. 17, n. 3, p. 339-344, 1999.

VIEIRA, E. A. Tamanho de sementes e sobrevivência de plântulas em áreas de pastagens degradadas. 2007. 68 f. Dissertação (Mestrado em Biologia Vegetal) Universidade Federal de Mato Grosso do Sul, Campo Grande, 2007.

VOLL, E. et al. Relações entre germinação de sementes de espécies de plantas daninhas e uso da condutividade elétrica. Planta Daninha, v. 21, n. 1, p. 181-189, 2003. 